\title{
Solar Updraft Power Technology: Fighting Global Warming and Rising Energy Costs
}

\author{
Wilfried B. Krätzig*
}

\author{
Ruhr-University Bochum, Department of Civil and Environmental Engineering, and Krätzig \& Partner \\ Consultants, Buscheyplatz 9-13, D-44801 Bochum, Germany
}

\begin{abstract}
Solar updraft power technology (SUPT) forms a highly innovative, modern and efficient concept for solarbased electricity generation. Solar updraft power plants (SUPPs) are fueled purely by solar irradiation. They require no water for power generation, so their ideal locations are deserts. A SUPP consists of the glass-covered collector area (CA), in its centre the solar chimney (SC), and around the SC's perimeter the power conversion units (PCU). This arrangement causes a permanent flow of warm air through the SUPP, producing electricity. The paper describes computer simulation concepts to evaluate the power/energy harvest in such plants, based on fluid-thermodynamics and radiation-physics. The nonlinear numerical processes for the SUPPs' power harvests are solved by fast computer algorithms. Finally, the high economy of SUPT for world-wide arid zones in terms of leveled electricity costs (LECs) is exemplified by several optimized SUPPs.
\end{abstract}

Keywords: Solar updraft power technology, multi-physics computer simulation, thermo-fluiddynamics, lowconcentrated solar power, cost-efficient electricity.

\section{INTRODUCTION}

Solar updraft power plants (SUPPs) like in Figure 1 represent a modern, highly innovative and economic generation technology for solar-based electricity. For their power/energy harvests, they require areas of (unused) desert, high solar chimneys, and suitable solar irradiation, all available in many countries between the two tropics. SUPPs are wind power plants, so they require no water for power production.

The working principle of SUPPs is schematically described in Figure 2. SUPPs consist of the greenhouse-like collector area (CA), the turbogenerators as power conversion units (PCUs), and the solar chimney (SC). In the CA, solar irradiation heats the ground absorber, in simplest case the natural soil. From there, emitted convective heat warms-up the air inside the collector, which expands, and streams towards the centre of the CA. There in the turbogenerators (PCUs), parts of the kinetic power of the warm airflow are transformed into electric power. Source of this moving air is the buoyancy of the (lighter) warm air in the SC, the plant's engine, creating a pressure sink at the PCUs' outlets. This updraft draws permanently fresh air into the collector from its rim, creating a continuous flow of air through the SUPP.

*Address correspondence to this author at the Ruhr-University Bochum, Department of Civil and Environmental Engineering, and Krätzig \& Partner Consultants, Buscheyplatz 9-13, D-44801 Bochum, Germany; Tel: +49 234 7099444; Fax: +49 234 7099419; E-mail: wilfried.b.kraetzig@kup-ing.de, kraetzig@kup-ing.de
Obviously, SUPPs are wind power plants [1] which produce their required airflow by use of thermal conversion of solar irradiation [2, 3], available at least as long as the sun shines. Thus the purpose of the glass roof over the CA is to allow a maximum of solar irradiation passing through, heating-up the absorber to high temperatures. Then, from the heated absorber, the internal air is warmed-up. Thus a second purpose of the glass roof is to prevent convective heat and IRradiation losses from the $C A$, escaping into the ambience: A high-tech optimization problem of modern glass technology!

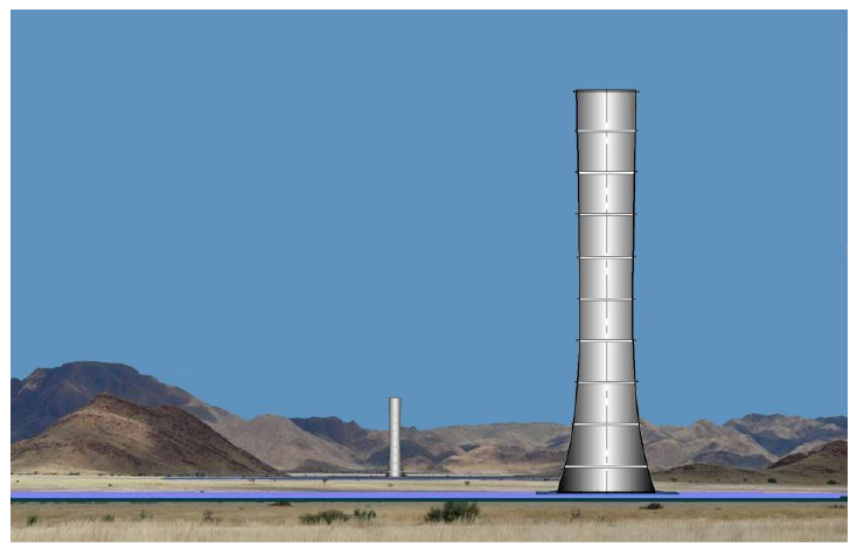

Figure 1: Computer vision of two SUPPs with $1000 \mathrm{~m}$ high solar chimneys.

SUPPs work most efficient in locations with annual solar irradiation $\geq 2.00 \mathrm{MWh} / \mathrm{m}^{2} \mathrm{a}$, occurring between the two tropics. But also the Mediterranean Europe with annual irradiation of $\approx 1.95 \mathrm{MWh} / \mathrm{m}^{2} \mathrm{a}$ offers fair locations. The efficiency of a SUPP depends on the solar irradiation, the size of the CA (air temperature) 
and the height of the SC (air buoyancy). For example, the SUPP in Figure 1 with CA diameter of $6000 \mathrm{~m}$ and SC height of $1000 \mathrm{~m}$ in a MENA-location will deliver a maximum electric power of $\approx 300 \mathrm{MW}_{\mathrm{p}}$, on midsummer noon, and an annual energy output of $\approx 800 \mathrm{GWh} / \mathrm{a}$.

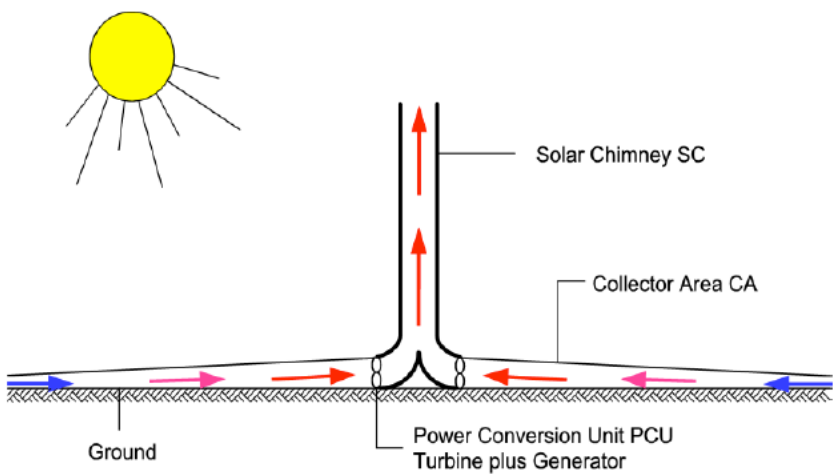

Figure 2: General working principle of SUPPS.

The present paper will elucidate the translation of the complicated multi-physics of the described nonlinear SUPP-processes into computer algorithms for plant designs. Thus it starts with the global mathematical modeling of the thermo-fluiddynamics. Then, the physics of the radiation/heat convection transfers in the collector are supplemented, compared to the full-scale SUPP treatment in meso-scale. The final highly nonlinear computer program requires combined incremental/iterative solution procedures. Ultimately, some typical power profiles of SUPPs are simulated, and estimates for the harvested electric energy as well as their generation costs close the treatment.

\section{THE GLOBAL FULL-SCALE THERMO-} FLUIDMECHANICAL SUPP MODEL

\subsection{General Assumptions of the Global SUPP Model}

As in industrial design of piping systems and chimneys, our global SUPP model shall be based on 1D flow-tube theory. Therein a control volume CV of air is prosecuted on its way through collector, turbines, and chimney, applying the following assumptions:

- The collector bottom is horizontal with equal ambient air pressure everywhere.

- All thermo-fluiddynamics is modeled as 1D (onedimensional).

- $\quad$ Air is assumed as an ideal gas due to eq. (2.6).

- $\quad$ All physics in the analysis model is approximated as stationary.
The final computer program will use hourly steps equivalent to the available dissolution of solar and temperature input data from meteorological services.

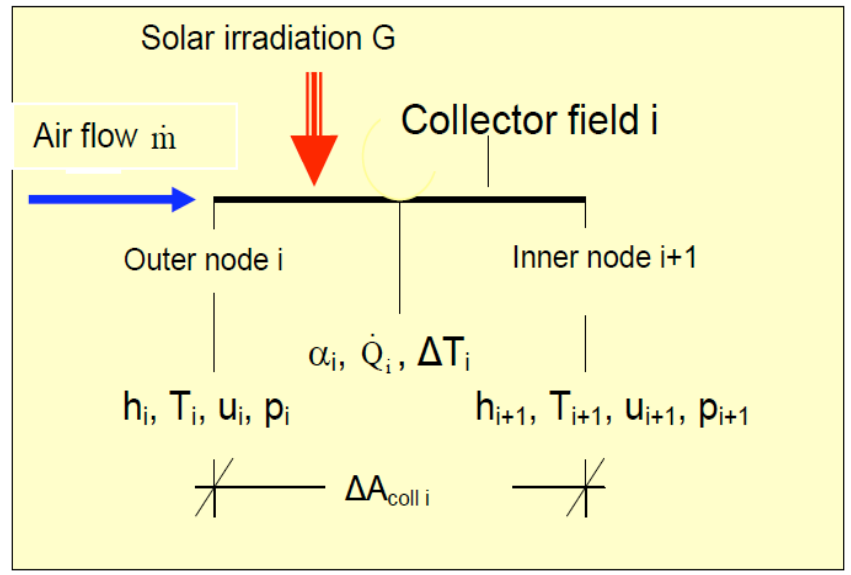

Figure 3: Discretized collector ring element $i$.

\subsection{Collector Model}

Figure 3 shows a 1D collector ring-element containing a characteristic $\mathrm{CV}$ of air at time $\mathrm{t}$, representing a collector ring volume of air with ground/top surfaces $\Delta A_{\text {coll } i}=\pi\left(r_{i+1}{ }^{2}-r_{i}^{2}\right)$. Its nodal points $i, i+1$ describe cylindrical bounding surfaces $A_{i}=$ $2 \pi r_{i} h_{i}, A_{i+1}=2 \pi r_{i+1} h_{i+1}$ of the airflow, in which $r_{i}, r_{i+1}$ denote distances from the chimney axis. $h_{i}, h_{i+1}$ stand for the respective internal collector heights [4].

The thermo-fluidmechanical processes in the collector can then be described by the following basic conditions:

Conservation of mass: $\dot{m}=$ const.,

Conservation of momentum:

$\dot{m} u_{i}-\dot{m} u_{i+1}+p_{i} A_{\text {coll } i}-p_{i+1} A_{\text {coll. } i+1}=0$,

Conservation of energy (extended BERNOULLI equation):

$p_{i}+0.5 \rho_{i} u_{i}^{2}+\rho_{i} c_{p} T_{i}=p_{i+1}+0.5 \rho_{i+1} u_{i+1}^{2}+\rho_{i+1} c_{p} T_{i+1}$,

extended by the thermal enthalpy term:

$\dot{Q}_{i}=\dot{m} c_{p} \Delta T_{i}$.

In these basic conditions, $\dot{m}$ abbreviates the mass flow rate of the CV of air $(\mathrm{kg} / \mathrm{s})$ through the plant, $u_{i}, u_{i+1}$ the air velocities $(\mathrm{m} / \mathrm{s}), p_{i}, p_{i+1}$ the air pressures $\left(\mathrm{N} / \mathrm{m}^{2}\right)$ at the airflow bounds $i, i+1, \dot{Q}_{i}$ the total specific heat flux (W) in the CV, and $\Delta T_{i}=T_{i+1}-T_{i}$ the temperature increase therein $(\mathrm{K}) . c_{p}$ abbreviates the specific heat capacity of air $(\mathrm{J} / \mathrm{kg} \mathrm{K})$. The equations are discretized for two different positions $i, i+1$ of finite distance. 
The solar irradiation $G\left(\mathrm{~W} / \mathrm{m}^{2}\right)$ is coupled to the total amount of enthalpy (heat) power $\dot{Q}_{i}$ in the collector by the following relations:

$\Delta \dot{Q}_{i}=\alpha_{i} G \Delta A_{\text {coll. }}, \Rightarrow \dot{Q}_{i}=\Sigma_{i} \Delta \dot{Q}_{i}$,

where $\alpha_{i}$ denotes a parameter interpreted as efficiency of the collector ring $\Delta A_{\text {coll.i } i}$ in transforming the solar irradiance $G$ into heat increase in the control volume of the collector airflow. In the further course, this $\alpha_{i}$ will serve as interface to the meso-scale treatment of solar heating of the collector air flux in the CA elements. It will be determined for each $\Delta A_{\text {coll.i, }}$ as described in Chapter 3.

The BERNOULLI equation (2.3) will be applied to connect the ambient pressure and velocity of the SUPP's ambience outside the collector rim with its interior values. Its extended form will additionally be applied to determine the flow pressure values in the collector interior. Assuming air as an ideal gas, we find by the gas law

$\rho_{i}=p_{i} / R T_{i}$

in which $R$ denotes the general gas constant $(\mathrm{J} / \mathrm{kg} \mathrm{K})$ of air and $T_{i}$ the absolute temperature $(\mathrm{K})$, a relation which couples the (mainly) fluidmechanical equations $(2.1,2.2,2.3)$ with the (mainly) thermodynamic conditions $(2.3,2.4,2.5)$.

\subsection{Chimney Model}

All previous conditions formulate, mathematically spoken, a nonlinear initial value problem. This can be solved by numerical integration over the collector distance $r$, starting at the collector's rim. At the turbines' outlets the air velocity $u_{\text {turb }}$ (or pressure $p_{\text {turb }}$ ) has to be coupled to that one in the chimney foot. These quantities in general can be evaluated from an independent initial value problem of the solar chimney, or just by applying an analytical solution of the chimney flow [5].

As in section 2.2 we again collect all necessary conditions for the chimney model:

Conservation of mass: $\dot{m}=$ const.,

Conservation of momentum: The SC transforms the air mass flow $\dot{m}$, heated in the collector by solar irradiation $G$, with its temperature increase $\Delta T_{\text {turb }}$ and pressure $p_{\text {turb }}$ into kinetic work, using the difference in air density, the buoyancy, as driving force:
$\Delta p=g \int_{0}^{H}\left\{\rho_{0}(h)-\rho_{i}(h)\right\} d h$.

Herein $\rho_{o}(h)$ and $\rho_{i}(h)\left(\mathrm{kg} / \mathrm{m}^{3}\right)$ stand for the heightdepending mass density of the air outside (index: 0 ) and inside (index: i) the chimney, $g$ for the gravitational acceleration $\left(\mathrm{m} / \mathrm{s}^{2}\right)$. Both density-profiles $\rho_{o}(h), \rho_{i}(h)$ influence the chimney's buoyancy. Modeling both profiles as standard meteorological atmospheres, $\rho_{i}(h)$ heated by $\Delta T$ constant over $h$, then eq. (2.8) can be analytically integrated over tower height $H$, leading to:

$\Delta p_{\max }=g \rho_{0} H \Delta T /\left(T_{0}+\Delta T\right)$.

The ${ }_{0}$-indexed quantities herein hold for the SUPP's ambience at chimney foot. Applying BERNOULLI's equation delivers the maximum air velocity at the chimney's entrance:

$u_{\max }=\sqrt{2 g H \Delta T /\left(T_{0}+\Delta T\right)}$.

Conservation of energy: Since the flow of warm air through the SC will not be harvested energetically in SUPPs, we can neglect this conservation condition.

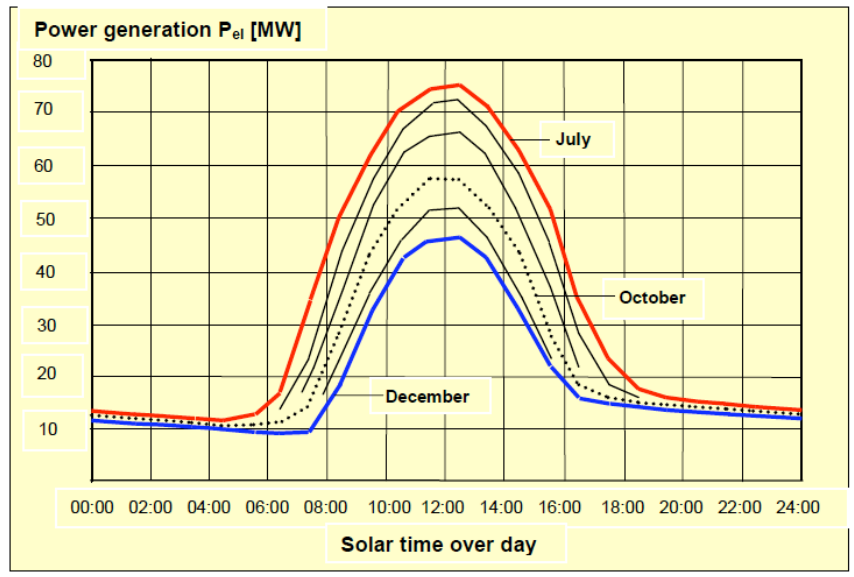

Figure 4: Generated $P_{\text {el }}$ eff for typical months July to December, 750/3500-SUPP.

\subsection{Turbine Model}

For our global thermo-fluidmechanical SUPP model, the essential physical process equations in the turbines are described by:

Conservation of mass: $\dot{m}=$ const.,

Conservation of energy: BERNOULLI's equation for the airflow in the turbine

$\Delta p_{\text {turb }}+\frac{1}{2} \rho u_{\text {turb }}^{2}=\Delta p_{\text {tot }}$ 
forms the basis of the turbine's layout [6]. With the pressure-withdrawal factor $\kappa$, and by use of the maximum velocity $u_{\max }$ from eq. (2.10), the following relations arise [7]:

$\Delta p_{\text {turb }}=\kappa \Delta p_{\text {tot }}: u_{\text {turb }}=\sqrt{1-\kappa} u_{\max }$

Herein $\Delta p_{\text {turb }}$ and $u_{\text {turb }}$ abbreviate average values of the pressure jump and the air velocity in the turbine, respectively.

[8] had proven, that $\Delta p_{\text {turb }}$ is not restricted by the BETZ power limit, since SUPP-turbines are ducted and not subject to open flows. Thus turbo-generator efficiencies $\eta_{\text {turb }}$ of $\geq 80 \%$ can be achieved. Finally, from the total power of the SUPP's maximum airflow

$P_{\text {tot }}=\dot{m} u_{\max }^{2} / 2$,

the harvested effective electric power $P_{e l}$ eff is found by multiplying $P_{\text {tot }}$ with $\eta_{\text {turb }}$ and $\kappa$ :

$P_{\text {el eff }}=\eta_{\text {turb }} \Delta p_{\text {turb }} \dot{m} / \rho=\eta_{\text {turb }} \kappa \dot{m} u_{\max }^{2} / 2$.

Figure 4 offers harvested electric work during different months for a SUPP with a $750 \mathrm{~m} \mathrm{SC}$ and a $3500 \mathrm{~m} \mathrm{CA}$ diameter, for $2.20 \mathrm{MWh} / \mathrm{m}^{2} \mathrm{a}$ of annual solar irradiation. Figure 5 shows a computer vision of the turbine openings of this SC.

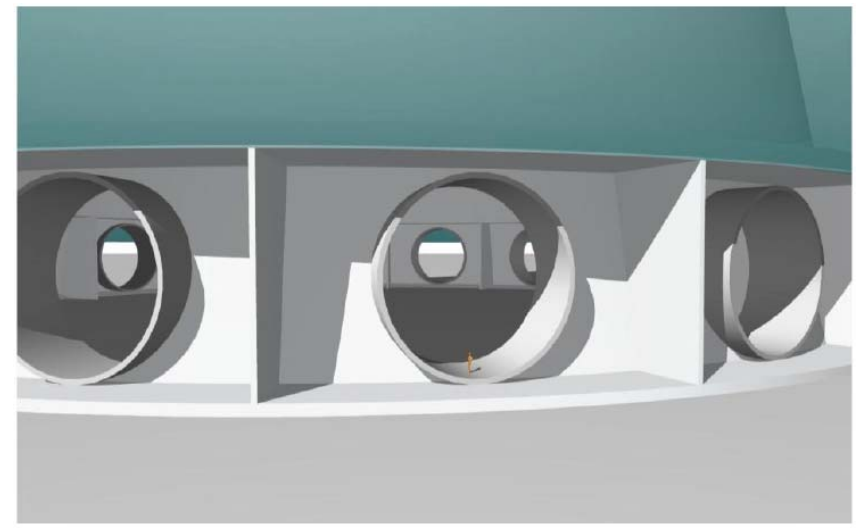

Figure 5: Computer vision of the chimney foot with turbine openings.

\subsection{Consideration of Flow Losses in Collector and Chimney}

Up to now, the model has been established without losses due to flow resistances in the collector, in the chimney, and due to the bent injection of the airflow into the chimney. All this reduces the flow pressures, and so the global efficiency of the SUPP. These losses are considered by identical concepts as applied in the design of industrial piping systems [9]. Finally, the evaluated pressure differences are subtracted from the loss-free pressures, such that the model then provides all actual pressures and velocities as well as the resulting electric powers under incorporation of the flow losses.

\subsection{Computer Simulation of the Global SUPP Behavior}

Sections 2.2, 2.3 and 2.4 contain the governing fluid-thermodynamic conditions of all plant components collector, chimney and turbo-generators. Discretizing the collector airflow and coupling of the values $\Delta p_{\max }$ resp. $u_{\max }$ from the chimney due to eqs. $(2.9,2.10)$, then incorporating the turbine condition (2.15), leads to a nonlinear initial value problem (NLIVP) in the mass flow of air $\dot{m}$. This NLIVP is nonlinear because of the nonlinear gas law (2.6), and the nonlinear coupling with eq. (2.9) or eq. (2.10).

Its solution requires incremental-iterative solutions and the element-wise knowledge of the still unknown collector efficiencies $\alpha_{i}$ (2.5). In earlier publications, $\alpha_{i}$ had been estimated or assumed as constant over the entire collector [3, 7]. To improve such approximations, this parameter shall now be determined from details of the collector/roof/absorber-construction in a mesoscale analysis concept. Thus now we formulate how in particular the thermal-radiation-transfers of the solar irradiation $G$ into heat flux $\dot{Q}$ of the collector airflow will be decisively influenced by design details of the collector.

\section{MESO-SCALE COMPLETION: CONVECTIVE/ RADIATIVE HEAT POWER TRANSFERS}

\subsection{General}

The collector design is most important for the efficiency of a SUPP, because efficient convective/radiation heat power transfers from $G$ into $\dot{Q}$ determine to a large extent the economy of the plant. The collector roof may consist of single or of double glass panels, the absorber may be plain ground soil, in natural color or artificially blackened, or improved by water-filled heat reservoirs. All such possible alternatives had been incorporated in Chapter 2 in the definition of the efficiency parameters $\alpha_{i}$.

In order to determine these $\alpha_{i}$, the physical transformation of solar irradiation $G$ into heat increase $\Delta T$ of the air flux $\dot{m}$ shall now to be modeled. Thereby, all mentioned details of the collector design are 
described in a meso-scale supplement compared to the global SUPP model of Chapter 2, and all exchanges of convective/radiation heat powers have to be considered in the heat power balance models of our simulation [10].

Here we will give a brief overview over the required formulae. Bases of the convective heat power transfers (qc) are well-known conditions like

$q c_{k}=h c_{k} \times T_{k}$

with the convective heat power transfer coefficients $h c_{k}$ from one collector component $k$ of absolute temperature $T_{k}$ to another one, all in the same collector element $i$. The convective heat transfer coefficients $h c_{k}$ can be found in professional handbooks of thermal engineering, available as standard literature.

The radiation heat transfers (qr) are based on PLANCK's and STEFAN-BOLTZMANN's radiation laws. The radiation transfers read between two parallel plates 1 and 2 [10].

$q r_{1}=q r_{2}=\frac{Q_{r}}{A}=\frac{\sigma \times\left(T_{2}^{4}-T_{1}^{4}\right)}{1 / \varepsilon_{1}+1 / \varepsilon_{2}-1}$,

or between one plate 1 and the sky

$q r_{1}=\varepsilon \times \sigma \times\left(T_{1}^{4}-T_{s k y}^{4}\right)$.

In both equations; the $\varepsilon$-values abbreviate optical emittances of opaque bodies, $T$ absolute temperatures and $\sigma$ the STEFAN-BOLTZMANN constant equal to $5.6697 \times 10^{-8}\left(\mathrm{~W} / \mathrm{m}^{2} \mathrm{~K}^{4}\right)$. Values for emittances $\varepsilon$ can be found in [10]. The sky temperature is estimated from observations by:

$T_{\text {sky }}=0.0552 \times\left(T_{0}\right)^{1.5}$

with $T_{0}$ as the ambient temperature of the SUPP environment.

\subsection{Power Balance Conditions of a Single-Glazed Collector}

We start with the heat power balance conditions of a single-glazed collector ring-element due to Figure $\mathbf{6}$, consisting of one panel of glass (Temperature: $T_{1}$ ), the airflow $\left(T_{2}\right)$ and the soil absorber $\left(T_{3}\right)$. The following thermal transfers $q r$ and $q c$ have to be distinguished due to eqs. (3.1) to (3.3), all depending on their respective temperatures:
- $q r_{\text {ougl }}$ radiation thermal transfer ( $q r$ ) from outer air (ou) into glass sheet ( $\mathrm{gl}$ ),

- $\quad q r_{\text {gl ou }}$ radiation thermal transfer from glass (gl) into outer air (ou),

- $\quad q r_{g l s o}$ radiation thermal transfer from glass (gl) into soil (so),

- $\quad q r_{\text {so gl }}$ radiation thermal transfer from soil (so) into glass $(\mathrm{gl})$

- $q c_{\text {ougl }}$ convective thermal transfer $(q c)$ from outer air (oa) into glass ( $\mathrm{gl}$ ),

- $q c_{g l}$ ou convective thermal transfer from glass (gl) into outer air (ou),

- $\quad q c_{g l \text { in }}$ convective thermal transfer from glass (gl) into inner air (in),

- $\quad q c_{\text {in } g l} \quad$ convective thermal transfer from inner air (in) into glass (gl)

- $\quad q c_{i n}$ so convective thermal transfer from inner air (in) into soil (so),

- $q c_{\text {so in }}$ convective thermal transfer from soil (so) into inner air (in),

- $q c_{\text {so so }}$ convection thermal transfer from absorber surface (so) into soil (so),

- $\quad$ si $_{\text {sugl }} \quad$ solar irradiation from the sun (su) into glass $(\mathrm{gl})(=G)$.

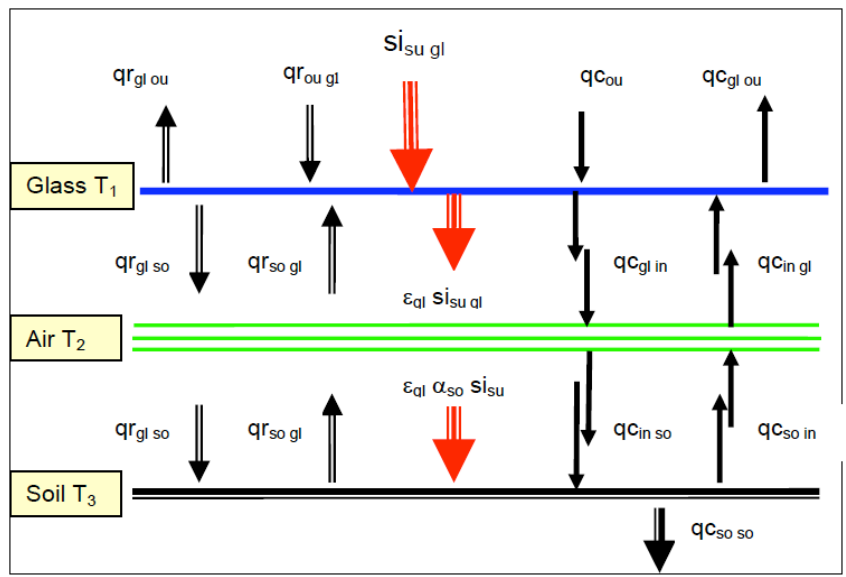

Figure 6: Scheme of heat transfers of a glass/air/soilcollector.

Assuming the total heat power transfers as stationary, then the total fluxes into the sheet of glass, the layer of airflow, and the soil absorber have to 
vanish. From these three power balance conditions, the convective heat transfers into the airflow, related to $G$, determine the desired efficiency coefficient $\alpha_{i}$ in the collector element $i$ :

glass: $q r_{\text {ou } g l}-q r_{g l ~ o u}-q r_{g l ~ s o}+q r_{\text {so gl }}+q c_{o u ~ g l}-q c_{g l \text { ou }}-$ $q c_{g l \text { in }}+q c_{\text {in } g l}+\left(1-\varepsilon_{g l}\right) s i_{\text {su gl }}=0$,

air: $q c_{g l \text { in }}-q c_{\text {in gl }}+q c_{s o \text { in }}-q c_{\text {in so }}=\alpha_{i} s i_{s u ~ g l}$

soil: $q r_{g l s o}-q r_{\text {so gl }}+q c_{\text {in so }}-q c_{\text {so in }}-q c_{\text {so so }}+\varepsilon_{g l} \alpha_{s o} s i_{s u g l}$ $=0$.

$\alpha_{s o}$ appearing in the last line denotes the broadband absorptance of the soil absorber. For this most simple collector construction we receive with the first and last equations (3.5) two coupled nonlinear algebraic conditions, depending on $4^{\text {th }}(q r)$ and $1^{\text {st }}(q c)$ powers of temperatures $T_{1}, T_{2}$ and $T_{3}$. The central equation of (3.5), obviously coupled to both others, contains only convective terms, and thus depends only on $1^{\text {st }}$ powers of the $T_{i k}$. It is formulated in such a way, that the heat flux increase

$\Delta \dot{q}_{i}=\alpha_{i} s i_{s u g l}$

of the internal airflow of the $i^{\text {th }}$ collector ring element is expressed directly by the desired efficiency parameter $\alpha_{i}$

The strongly nonlinear algebraic sets (3.5) of heat power balance conditions for each $i$ collector ring element $\Delta A_{\text {coll.i }}$ have to be solved simultaneously with the incremental analysis of the NLIVP for the entire SUPP, leading to a considerable computing effort.

\subsection{Power Balance Conditions of a Double-Glazed Collector}

For more complicated collector designs the number of heat power balance conditions increases leading to higher computing efforts [7, 11]. For demonstration, the formulation of the power balance conditions will now be performed for a double glazing collector due to Figure 7. Therein, $T_{1}$ denotes the temperature of the outer glass panels, $T_{2}$ that one of the inner panels. $T_{3}$ is the temperature of the inner air and $T_{4}$ that one of the absorber surface. Then we have analogously to section 3.2 the following heat fluxes:

- $q r_{\text {ou glo }}$ radiation thermal transfer $(q r)$ from outer air (ou) into outer glass (glo),

- $q r_{\text {glo ou }}$ radiation thermal transfer from outer glass (glo) into outer air (ou),
- $\quad g r_{\text {glo gli }}$ radiation thermal transfer from outer glass (glo) into inner glass (gli),

- $q r_{\text {gli glo }}$ radiation thermal transfer from inner glass (gli) into outer glass (glo),

- $q r_{\text {gliso }}$ radiation thermal transfer from inner glass (gli) into soil (so),

- $\quad q r_{\text {so gli }}$ radiation thermal transfer from soil (so) into inner glass (gli),

- $q c_{\text {ouglo }}$ convective thermal transfer $(q c)$ from outer air (ou) into outer glass (glo),

- $\quad q c_{\text {glo ou }}$ convective thermal transfer from outer glass (glo) into outer air (ou),

- $\quad q c_{\text {glo gli }}$ convective thermal transfer $(q c)$ from outer glass (glo) into inner glass (gli),

- $q c_{\text {glo gli }}$ convective thermal transfer from inner glass (gli) into outer glass (glo),

- $\quad q c_{\text {gli in }}$ convective thermal transfer from inner glass (gli) into inner air (in),

- $\quad q c_{\text {in gli }}$ convective thermal transfer from inner air (in) into inner glass (gli),

- $\quad q c_{\text {in so }}$ convective thermal transfer from inner air (in) into soil absorber (so),

- $q c_{\text {so in }}$ convective thermal transfer from soil absorber (so) into inner air (in),

- $q c_{\text {soso }}$ convection thermal transfer from absorber surface (so) into soil (so),

- $\quad s i_{\text {suglo }}$ solar irradiation from the sun (su) into outer glass (glo) $(=G)$.

There exist now four thermal balance conditions which read as follows:

outer glass: $q r_{\text {ou glo }}-q r_{\text {glo ou }}-q r_{\text {glo gli }}+q r_{\text {gli glo }}+q c_{\text {ou glo }}-$ $q c_{\text {glo ou }}-q c_{\text {glo gli }}+q c_{\text {gli glo }}+\left(1-\varepsilon_{g l o}\right) s i_{s u}$ glo $=0$,

inner glass: $q r_{g l o} g l i-q r_{g l i} g l o-q r_{g l i}$ so $+q r_{\text {so gli }}+q c_{g l o}$ gli $q c_{\text {gli glo }}-q c_{\text {gli in }}+q c_{\text {in gli }}+\varepsilon_{\text {glo }} s i_{\text {su glo }}-\varepsilon_{\text {glo }} \varepsilon_{\text {gli }} s i_{\text {su glo }}=0$,

air: $q c_{\text {gli in }}-q c_{\text {in gli }}+q c_{\text {so in }}-q c_{\text {in so }}=\alpha_{i} s_{\text {su glo }}$,

soil: $q r_{\text {gli so }}-q r_{\text {so gli }}+q c_{\text {in so }}-q c_{\text {so in }}-q c_{\text {so so }}+\varepsilon_{g l o} \varepsilon_{g l i} \varepsilon_{s o}$ $\alpha_{\text {so }} s i_{\text {su glo }}=0$.

This set of four nonlinear algebraic equations has again to be solved simultaneously with the NLIVP of 
the global SUPP. We observe that, as in section 3.2, from the linear condition for the internal air the parameter $\alpha_{i}$ can be determined.

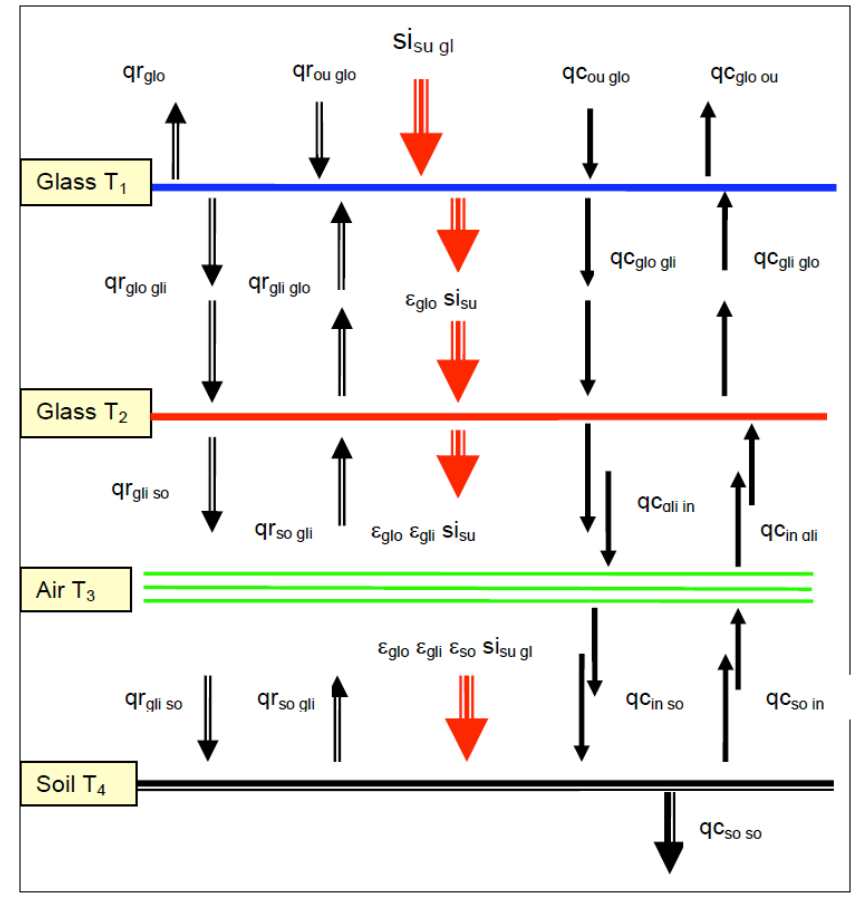

Figure 7: Scheme of heat transfers of a glass/glass/air/soilcollector.

\subsection{Simulation of the Entire Plant Behavior}

If we now overlook chapters 2 and 3 , we observe the multiple nonlinearities in the equations, which require stable incremental-iterative solution strategies. For this we start with the global fluid-thermodynamic NLIVP of the eqs. (2.1) - (2.14) in the mass flow rate $\dot{m}$, see section 2.6. Given $G$ and $T_{0}$, a starter set of efficiencies $\alpha_{i}>0$, one value for each ring-element $i$, is selected and the NLIVP is solved. This leads to a first approximation of temperatures $T_{2 i}$ or $T_{3 i}$ of the airflow in each collector element $\Delta A_{\text {coll.i. }}$. These air temperatures are transferred into the sets of nonlinear heat power balance conditions $(3.5,3.7)$ of all collector elements, resulting after their iterative solution in a new approximation of the efficiencies $\alpha_{i}$. With this improved set of $\alpha_{i}$ the solution of the global NLIVP is repeated leading to new air temperatures $T_{2 i}$ or $T_{3 i}$. This total iteration is repeated until the difference of two consecutive $P_{\text {el eff }}$ remains below a given bound.

The described solution process is coded in EXCEL and embedded in VISUAL BASIC. Centre of the nonlinear solutions is the EXCEL modulus SOLVER. This EXCELadd-in, developed for optimization problems, works incrementally-iteratively. Because it contains NEWTON-
RAPHSON-procedures and gradient-methods, it is excellently suited for solutions of strongly nonlinear problems. All following numerical examples are simulated by software codes on this basis [4].

\section{ANALYSIS OF SUPPS WITH 500 M AND $750 \mathrm{M}$ CHIMNEYS}

\subsection{Different Roles of SUPP Components}

Because of its warm air updraft, the SC is the power source of each SUPP, its engine. In order to create a maximum of buoyancy, the SC has to be fed from the collector with airflow of highest possible temperature increase $\Delta T$ at the turbines' exits. So the most important component of a SUPP is the collector as heater of the inner airflow.

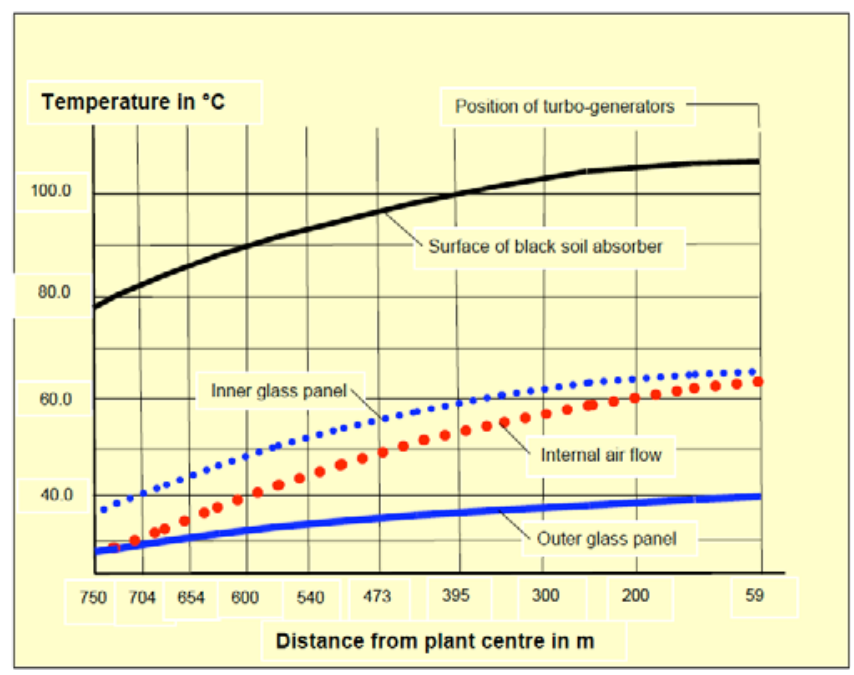

Figure 8: Temperatures of glass panels, air and collector soil, 500/1500-SUPP.

Figure 8 maps the temperatures in the collector for a small SUPP with SC height of $500 \mathrm{~m}$, diameter of $55.00 \mathrm{~m}$ in the throat, and CA diameter of $1500 \mathrm{~m}$. The collector height starts with initial $5.00 \mathrm{~m}$ at the outer rim and increases to $\approx 12.00 \mathrm{~m}$ at the turbines' inlets. The collector roof consists of double sheets of specially coated white glass with an insulating distance of 20 $\mathrm{mm}$. The absorber is blackened by sprayed concrete color. $G=1000 \mathrm{~W} / \mathrm{m}^{2}$ and an ambient temperature of $25^{\circ} \mathrm{C}$ produce the situation on Figure 8 .

Obviously, the outer glass panels increase their temperatures from $25^{\circ} \mathrm{C}$ at the collector rim to $\approx 40^{\circ} \mathrm{C}$ at the turbines. The inner glass panels get much warmer because of the insulating air layer, from $25^{\circ} \mathrm{C}$ to $\approx 65^{\circ} \mathrm{C}$. The hottest collector element is the surface of the soil absorber, heated up by $\mathrm{G}$ to $106^{\circ} \mathrm{C}$ at the turbine's entries, a consequence of the (nano-pigmented) black 
Table 1: Hourly Values of Ambient Temperatures $\mathrm{T}_{0}$ and Total Solar Irradiation $\mathrm{G}$

\begin{tabular}{|c|c|c|c|c|c|c|c|c|c|c|c|c|}
\hline \multirow{2}{*}{$\begin{array}{l}\text { Solar } \\
\text { Time }\end{array}$} & \multicolumn{2}{|c|}{ January } & \multicolumn{2}{|c|}{ April } & \multicolumn{2}{|c|}{ July } & \multicolumn{2}{|c|}{ September } & \multicolumn{2}{|c|}{ October } & \multicolumn{2}{|c|}{ December } \\
\hline & $\mathrm{T}_{0}\left[{ }^{\circ} \mathrm{C}\right]$ & $\mathrm{G}\left[\mathrm{W} / \mathrm{m}^{2}\right]$ & $\mathrm{T}_{0}\left[{ }^{\circ} \mathrm{C}\right]$ & $\mathrm{G}\left[\mathrm{W} / \mathrm{m}^{2}\right]$ & $\mathrm{T}_{0}\left[{ }^{\circ} \mathrm{C}\right]$ & $\mathrm{G}\left[\mathrm{W} / \mathrm{m}^{2}\right]$ & $\mathrm{T}_{0}\left[{ }^{\circ} \mathrm{C}\right]$ & $\mathrm{G}\left[\mathrm{W} / \mathrm{m}^{2}\right]$ & $\mathrm{T}_{0}\left[{ }^{\circ} \mathrm{C}\right]$ & $\mathrm{G}\left[\mathrm{W} / \mathrm{m}^{2}\right]$ & $\mathrm{T}_{0}\left[{ }^{\circ} \mathrm{C}\right]$ & $\mathrm{G}\left[\mathrm{W} / \mathrm{m}^{2}\right]$ \\
\hline 1 & 14.06 & 0 & 22.09 & 0 & 25.25 & 0 & 22.59 & 0 & 18.19 & 0 & 13.16 & 0 \\
\hline 2 & 13.63 & 0 & 21.66 & 0 & 25.09 & 0 & 22.16 & 0 & 17.76 & 0 & 12.73 & 0 \\
\hline 3 & 13.20 & 0 & 21.23 & 0 & 24.66 & 0 & 21.73 & 0 & 17.33 & 0 & 12.30 & 0 \\
\hline 4 & 12.77 & 0 & 20.80 & 0 & 24.33 & 0 & 21.30 & 0 & 16.90 & 0 & 11.87 & 0 \\
\hline 5 & 12.34 & 0 & 20.37 & 0 & 23.80 & 144 & 20.87 & 0 & 16.47 & 0 & 11.44 & 0 \\
\hline 6 & 11.91 & 0 & 19.94 & 190 & 23.37 & 270 & 20.44 & 164 & 16.04 & 0 & 11.01 & 0 \\
\hline 7 & 11.48 & 140 & 19.51 & 417 & 22.94 & 500 & 20.01 & 314 & 15.61 & 206 & 10.58 & 125 \\
\hline 8 & 11.05 & 345 & 19.08 & 640 & 22.51 & 718 & 19.58 & 539 & 15.18 & 418 & 10.15 & 292 \\
\hline 9 & 10.62 & 531 & 19.40 & 824 & 24.10 & 892 & 20.70 & 748 & 16.50 & 615 & 09.72 & 472 \\
\hline 10 & 11.40 & 670 & 21.50 & 954 & 25.90 & 1020 & 22.80 & 889 & 18.30 & 747 & 11.30 & 597 \\
\hline 11 & 13.80 & 728 & 23.30 & 1008 & 27.60 & 1083 & 24.50 & 949 & 20.60 & 821 & 13.60 & 650 \\
\hline 12 & 15.70 & 734 & 24.80 & 1010 & 29.00 & 1089 & 25.90 & 952 & 22.00 & 824 & 15.40 & 658 \\
\hline 13 & 17.00 & 683 & 25.90 & 953 & 30.00 & 1021 & 26.80 & 889 & 23.00 & 741 & 16.50 & 608 \\
\hline 14 & 17.90 & 544 & 26.60 & 833 & 30.50 & 904 & 27.40 & 746 & 23.60 & 627 & 17.30 & 473 \\
\hline 15 & 18.30 & 347 & 26.90 & 649 & 30.70 & 731 & 27.50 & 550 & 23.90 & 411 & 17.70 & 319 \\
\hline 16 & 18.20 & 132 & 26.90 & 417 & 30.50 & 520 & 27.30 & 325 & 23.60 & 141 & 17.50 & 133 \\
\hline 17 & 17.50 & 0 & 26.30 & 141 & 30.10 & 346 & 26.50 & 136 & 23.00 & 0 & 16.60 & 0 \\
\hline 18 & 17.07 & 0 & 25.10 & 0 & 29.30 & 146 & 25.60 & 0 & 21.20 & 0 & 16.17 & 0 \\
\hline 19 & 16.64 & 0 & 24.67 & 0 & 28.10 & 0 & 25.17 & 0 & 20.77 & 0 & 15.74 & 0 \\
\hline 20 & 16.21 & 0 & 24.24 & 0 & 27.67 & 0 & 24.74 & 0 & 20.34 & 0 & 15.31 & 0 \\
\hline 21 & 15.78 & 0 & 23.81 & 0 & 27.24 & 0 & 24.31 & 0 & 19.91 & 0 & 14.88 & 0 \\
\hline 22 & 15.35 & 0 & 23.38 & 0 & 26.81 & 0 & 23.88 & 0 & 19.48 & 0 & 14.45 & 0 \\
\hline 23 & 14.92 & 0 & 22.95 & 0 & 26.38 & 0 & 23.45 & 0 & 19.05 & 0 & 14.02 & 0 \\
\hline 24 & 14.49 & 0 & 22.52 & 0 & 25.95 & 0 & 23.02 & 0 & 18.62 & 0 & 13.59 & 0 \\
\hline
\end{tabular}

soil. So the collector is designed such that the internal air, the SUPP's working medium, is heated from both sides: Mainly from below by the hot absorber surface, but also from above by the warmer inner glass sheets [4].

\subsection{Simulated Energy Outputs of $500 \mathrm{~m} / 2000 \mathrm{~m}$ SUPPs}

We now take a look into optimization studies which have been carried out at Krätzig \& Partner Consultants within the last years. We start with the $500 \mathrm{~m}$ SC SUPP family. All chimneys of height $500 \mathrm{~m}$ have throat diameters of $45.00 \mathrm{~m}$, and top openings of $50.00 \mathrm{~m}$. The base diameters read $100.00 \mathrm{~m}$. The outer collector diameter of the optimum SUPP is $2000 \mathrm{~m}$ wide. Its internal height starts with $4.00 \mathrm{~m}$ and reaches an elevation of $\approx 19.00 \mathrm{~m}$ at the turbines' entries [12]. All named dimensions lead to minimum electricity generation expenses in terms of leveled electricity costs (LECs).

The collector roof again is double-glazed, with 20 $\mathrm{mm}$ of insulating air, and the soil absorber is sprayed black. All plants had an annual global solar irradiation of $\mathrm{G}=2.20 \mathrm{MWh} / \mathrm{m}^{2} \mathrm{a}$. Daily irradiation and ambient temperatures profiles are similar to those ones published in [13], a selection of both sets of values can be found in Table 1.

Table 2 contains the generated electric power under the meteorological conditions of Table $\mathbf{1}$ in hourly intervals. One observes a maximum power of 23.24 MW around noon in July. Integration over the year leads to an annual electric work of $74.42 \mathrm{GWh} / \mathrm{a}$. As already seen in Figure 4, we confirm in Table 2 the 
Table 2: Hourly Values of the Computed Electric Power [MW] of the 500/2000-SUPP

\begin{tabular}{|c|c|c|c|c|c|c|}
\hline Solar Time & January & April & July & September & October & December \\
\hline 1 & 2.49 & 3.54 & 3.99 & 3.35 & 2.74 & 2.19 \\
\hline 2 & 2.50 & 3.51 & 3.82 & 3.34 & 2.74 & 2.20 \\
\hline 3 & 2.51 & 3.51 & 3.81 & 3.34 & 2.75 & 2.22 \\
\hline 4 & 2.55 & 3.53 & 3.79 & 3.35 & 2.78 & 2.25 \\
\hline 5 & 2.58 & 3.57 & 5.00 & 3.38 & 2.81 & 2.29 \\
\hline 6 & 2.62 & 4.48 & 7.07 & 5.78 & 2.84 & 2.30 \\
\hline 7 & 4.36 & 8.08 & 10.41 & 7.82 & 6.57 & 2.32 \\
\hline 8 & 7.09 & 12.23 & 14.31 & 11.10 & 9.12 & 4.40 \\
\hline 9 & 10.47 & 16.04 & 17.41 & 14.38 & 11.85 & 8.21 \\
\hline 10 & 13.34 & 18.73 & 20.09 & 17.10 & 14.21 & 10.98 \\
\hline 11 & 14.93 & 20.68 & 22.05 & 19.16 & 16.26 & 12.74 \\
\hline 12 & 15.93 & 21.80 & 23.20 & 20.36 & 17.49 & 13.88 \\
\hline 13 & 16.15 & 22.01 & 23.34 & 20.60 & 17.53 & 14.23 \\
\hline 14 & 15.11 & 21.20 & 22.58 & 19.59 & 16.65 & 13.26 \\
\hline 15 & 12.85 & 19.28 & 20.80 & 17.48 & 14.32 & 11.39 \\
\hline 16 & 9.69 & 16.27 & 18.13 & 14.41 & 10.72 & 8.74 \\
\hline 17 & 6.79 & 12.28 & 15.17 & 11.13 & 7.41 & 6.15 \\
\hline 18 & 4.99 & 8.87 & 11.83 & 8.02 & 5.84 & 4.49 \\
\hline 19 & 3.91 & 6.63 & 8.71 & 6.05 & 4.51 & 3.49 \\
\hline 20 & 3.26 & 5.29 & 6.65 & 4.87 & 3.72 & 2.90 \\
\hline 21 & 2.89 & 4.49 & 5.43 & 4.18 & 3.25 & 2.55 \\
\hline 22 & 2.67 & 4.03 & 4.70 & 3.77 & 2.99 & 2.35 \\
\hline 23 & 2.56 & 3.76 & 4.28 & 3.54 & 2.84 & 2.25 \\
\hline 24 & 2.51 & 3.61 & 4.04 & 3.41 & 2.76 & 2.20 \\
\hline
\end{tabular}

inherent heat storage capacity of the soil absorber allowing also electricity production after sun set. [14] had extended this storage capacity by technical means, such that also SUPPs can be designed for base load service as well as for peak load service. Such technical means are (controlled) water storage devices due to [2, 15] or double-compartment collectors [14].

\subsection{Simulated Energy Output for a $750 \mathrm{~m} / 3500 \mathrm{~m}$ SUPP}

We now supplement section 4.2 by the power production of a SUPP with $750 \mathrm{~m}$ high SC and a CA with $3500 \mathrm{~m}$ outer diameter. The top opening of the chimney is $75.00 \mathrm{~m}$ wide, the throat $67.50 \mathrm{~m}$, and the base diameter $135.00 \mathrm{~m}$. Again the collector starts with an internal height of $4.00 \mathrm{~m}$, which increases towards the turbines to $26.50 \mathrm{~m}$. The collector will be doubleglazed, and the soil absorber is blackened. The SUPP will be subjected again by solar irradiation and ambient temperatures from Table 1.
The simulated electric powers are listed in Table 3. By expectation, they are much higher than those ones of the 500/2000-SUPP, with a maximum of $100.90 \mathrm{MW}$, briefly after noon in July. The annual electric work had been simulated to $326.92 \mathrm{MWh} / \mathrm{a}$.

\section{POWER / ENERGY OPTIMIZATION, CAPITAL INVESTMENT AND LECS}

The examples given in sections 4 and the comparisons in this chapter stem from series of optimization studies for SUPPs carried out by Krätzig \& Partner Consultants. All SUPPs therein were considered in a location with annual total (beam + diffuse) solar irradiation of $2.20 \mathrm{MWh} / \mathrm{m}^{2} \mathrm{a}$. The optimizations were focused on chimney dimensions, collector sizes, glass properties of the collector roof, attributes of the soil absorber, and investment conditions. Their aims were minimum values of the leveled electricity costs LECs due to IEA-guidelines. All these computer simulations confirmed that the costs of energies harvested in SUPPs are considerable lower 
Table 3: Hourly Values of the Computed Electric Power [MW] of the 750/3500-SUPP

\begin{tabular}{|c|c|c|c|c|c|c|}
\hline Solar Time & January & April & July & September & October & December \\
\hline 1 & 10.71 & 15.47 & 17.51 & 14.62 & 11.84 & 9.65 \\
\hline 2 & 10.74 & 15.34 & 16.74 & 14.52 & 11.82 & 9.59 \\
\hline 3 & 10.80 & 13.33 & 16.68 & 14.53 & 11.89 & 9.62 \\
\hline 4 & 10.97 & 15.40 & 16.57 & 14.61 & 12.00 & 9.72 \\
\hline 5 & 11.12 & 15.51 & 21.97 & 14.73 & 12.15 & 9.85 \\
\hline 6 & 11.29 & 19.63 & 31.14 & 25.44 & 12.31 & 10.01 \\
\hline 7 & 15.83 & 35.56 & 45.81 & 34.44 & 28.93 & 10.18 \\
\hline 8 & 29.26 & 53.72 & 62.70 & 48.84 & 40.18 & 20.24 \\
\hline 9 & 44.95 & 70.14 & 75.97 & 63.05 & 52.13 & 29.26 \\
\hline 10 & 57.92 & 81.59 & 87.30 & 74.66 & 62.34 & 42.21 \\
\hline 11 & 65.06 & 89.84 & 95.50 & 83.41 & 71.12 & 51.91 \\
\hline 12 & 69.54 & 94.54 & 100.28 & 88.48 & 76.37 & 58.17 \\
\hline 13 & 70.62 & 95.43 & 100.90 & 89.52 & 76.58 & 62.30 \\
\hline 14 & 66.22 & 92.07 & 97.77 & 85.31 & 72.88 & 63.36 \\
\hline 15 & 56.54 & 84.05 & 90.38 & 76.43 & 62.92 & 58.92 \\
\hline 16 & 42.83 & 71.32 & 79.18 & 63.32 & 47.34 & 50.66 \\
\hline 17 & 30.04 & 54.16 & 66.61 & 49.16 & 32.83 & 39.00 \\
\hline 18 & 22.03 & 39.29 & 52.21 & 35.54 & 25.84 & 27.53 \\
\hline 19 & 17.17 & 29.39 & 38.57 & 26.81 & 19.90 & 20.07 \\
\hline 20 & 14.26 & 23.40 & 29.49 & 21.53 & 16.33 & 15.59 \\
\hline 21 & 12.55 & 19.82 & 24.01 & 18.38 & 14.21 & 12.84 \\
\hline 22 & 11.57 & 17.70 & 20.74 & 16.53 & 12.99 & 11.26 \\
\hline 23 & 11.04 & 16.48 & 18.82 & 15.47 & 12.31 & 10.36 \\
\hline 24 & 10.79 & 15.81 & 17.73 & 14.90 & 11.97 & 9.87 \\
\hline
\end{tabular}

then those ones from competitive renewable energy technologies. Detail of these optimization studies would exceed the scope of this manuscript. Instead we will present results for SUPP-families of $500 \mathrm{~m}$ and of 750 $\mathrm{m}$ of chimney height, as exemplified in chapter 4 . A similar study for $1000 \mathrm{~m}$ SUPPs has recently been published in [16], leading to comparable results.

The SC heights of the first SUPP configuration are all $500 \mathrm{~m}$, their shell diameters/shell thicknesses range from $50.00 \mathrm{~m} / 25 \mathrm{~cm}$ (top) over $45.00 \mathrm{~m} / 25 \mathrm{~cm}$ (throat) to $100.00 \mathrm{~m} / 40 \mathrm{~cm}$ (bottom). All chimney shells are reinforced by 3 external stiffening rings and an upper edge member. The outer collector diameters in the study varied from $1500 \mathrm{~m}$ to $2500 \mathrm{~m}$; the collector heights started from $4.00 \mathrm{~m}$ at the outer rim increasing until $12.00 \mathrm{~m}$ to $19.00 \mathrm{~m}$ at the turbine entries. 16 turbo-generators of $9.00 \mathrm{~m}$ of diameter transform the kinetic power of the airflow into electricity.

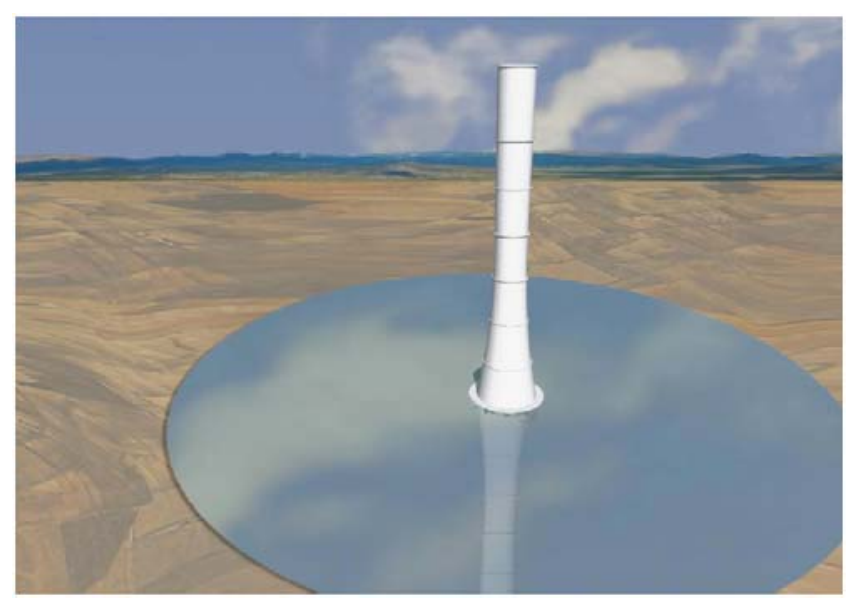

Figure 9: Computer vision of a member of the $750 \mathrm{~m}$ SUPP configuration.

All chimney heights of the second plant configuration are $750 \mathrm{~m}$, their shell diameters/shell thicknesses range from $75.00 \mathrm{~m} / 28 \mathrm{~cm}$ (top) over 67.50 
Table 4: Results of the Optimization Study for Two SUPP Configurations ( $\mathrm{G}=2.20 \mathrm{MWh} / \mathrm{m}^{2} \mathrm{a}$ )

\begin{tabular}{|c|c|c|c|c|}
\hline & $\begin{array}{c}500 / 2000 \\
\text { Mean }\end{array}$ & $\begin{array}{l}500 / 2000 \\
\text { Maximum }\end{array}$ & $\begin{array}{c}750 / 3500 \\
\text { Mean }\end{array}$ & $\begin{array}{c}750 / 3500 \\
\text { Maximum }\end{array}$ \\
\hline Chimney height [m] & 500.00 & & 750.00 & \\
\hline Top diameter of chimney [m] & 55.00 & & 75.00 & \\
\hline Throat diameter of chimney [m] & 50.00 & & 67.50 & \\
\hline Base diameter of chimney [m] & 115.00 & & 135.00 & \\
\hline Outer collector diameter [m] & 2000.00 & & 3500.00 & \\
\hline Total annual electric work harvest [GWh/a] & 63.26 & 74.42 & 261.54 & 326.92 \\
\hline Maximum electric power $\mathrm{P}_{\mathrm{el} \max }[\mathrm{MW}]$ & 19.75 & 23.24 & 80.72 & 100.90 \\
\hline \multicolumn{5}{|l|}{ Investments: } \\
\hline Chimney [M€] & 23.9 & 23.9 & 62.5 & 62.5 \\
\hline Double glazed collector $\left(22.50 € / \mathrm{m}^{2}\right)[\mathrm{M} €]$ & 70.7 & 70.7 & 216.5 & 216.5 \\
\hline Turbo.generators $\left(0.65 \mathrm{M} € / \mathrm{P}_{\mathrm{el} \max }\right)[\mathrm{M} €]$ & 12.8 & 15.1 & 52.5 & 65.6 \\
\hline Engineering + Additionals + Tests $[\mathrm{M} €]$ & 6.4 & 6.6 & 19.9 & 20.7 \\
\hline Total investments [M€] & 113.8 & 116.3 & 351.4 & 365.3 \\
\hline Annuity including annual insurance $[\mathrm{M} €]$ & 7.6 & 7.8 & 23.5 & 24.5 \\
\hline LECs for 30 years of depreciation [€/kWh] & 0.121 & 0.105 & 0.090 & 0.075 \\
\hline
\end{tabular}

$\mathrm{m} / 28 \mathrm{~cm}$ (throat) to $135.00 \mathrm{~m} / 50 \mathrm{~cm}$ (bottom). Here the SC shells are reinforced by 5 external rings and an upper edge member. The outer collector diameters varied from $2500 \mathrm{~m}$ to $4000 \mathrm{~m}$; the collector heights also start from $4.00 \mathrm{~m}$ at the outer rim increasing until $15.00 \mathrm{~m}$ up to $27.00 \mathrm{~m}$. 16 turbo-generators of $16.00 \mathrm{~m}$ of diameter each deliver electric power [12, 17]. Figure 9 shows a computer vision of a member of this SUPP family.

All collectors are roofed with double sheets of pure white glass from standard industrial production lines, 6 $\mathrm{mm}$ thick and mounted with $20 \mathrm{~mm}$ of airtight space. The light-transmittances are optimized such that $\tau_{g}$ out $=$ 0.93 and $\tau_{g}$ int $=0.92$. All outer faces of the external glazing resp. all inner faces of the internal one are coated to prevent reflection of solar irradiance respectively of IR-radiation. The soil absorber is again artificially blackened by sprayed concrete pigments for a broadband absorptance of $\alpha_{\text {soil }}=0.93$. For the costestimates in Table $\mathbf{4}$ it is assumed, that the plant site is rather plane, requiring only insignificant leveling works, further that the site is provided cost-free by the client, because SUPPs will be located in unused desert. To exclude influences of the geographical location, no transportation costs outside the plant site are considered.

Table 4 summarizes the studies by comparing those two SUPP configurations which led to the minimum
LECs. The cost positions Engineering + Additionals + Tests is assumed to $6.0 \%$ of the three positions ahead, and the position Annuity including annual assurance to $6.7 \%$ of the total investments, all values taken from earlier and much more detailed cost calculations by Krätzig \& Partner Consultants. As expected, Table 4 contains rather low LECs, at the utmost $0.075 € / \mathrm{kWh}$. For the annual electric energies as for the maximum powers, the optimization generated - by expectation rather high values, denoted as maximum in Table 4. They may not be repeated in daily designs. To compensate this, $85 \%(80 \%)$ of the maximum harvests are assumed as mean values.

\section{SUMMARY AND OUTLOOK}

As we may have convinced the reader by the previous treatment, SUPT has a couple of advantages compared to other renewable power technologies. The main ones are:

- It transforms both global as well as diffuse parts of solar irradiation into electricity.

- It requires no water for this transformation, neither for steam generation nor for steam recondensation, since SUPPs are wind power plants which generate their required airflows themselves from solar irradiation. 
- $\quad$ SUPPs can be extended without any extraneous technology for electricity production after sunset.

- $\quad$ SUPT seems to be the cheapest technology in producing solar electricity.

In the literature further benefits of SUPPs can be found, like climate improvements [18].

Since Schlaich's experimental SUPP 1982 in MANZANARES/SPAIN [3] immense research progress has been reached in SUPT [19, 20], like in mathematical modeling of SUPPs, computer simulations, wind engineering of SCs, glass technology, etc. This is one of the reasons for efficiency jumps leading to decrease of predicted production costs LECs.

What will bring the future for this technology? Already presently, the LECs of competitive renewable electricity technologies (CSP, PV, wind) lie considerably higher. Anticipating scaling effects of plant sizes, LECs for SUPPs will definitely lie below those ones for LECs of classical fossil or nuclear sources. Looking a last time on Table 4, the LECs there hold only for the first plant's depreciation period of 30 years. After this period until termination of the SUPPs' service lives ( $\geq 120$ years), LECs will decrease to less than 0.04 $€ / \mathrm{kWh}$, because of few repairs and low maintenance costs.

\section{NOMENCLATURE}

$$
\begin{aligned}
& \text { G } \quad=\text { Solar irradiance }\left(\mathrm{W} / \mathrm{m}^{2}\right) \\
& u \quad=\text { Internal air velocities in collector, } \\
& \text { chimney and turbine }(\mathrm{m} / \mathrm{s}) \\
& p \\
& \dot{q}_{i}, \dot{Q}_{i} \\
& \Delta \dot{q}_{i}, \Delta \dot{Q}_{i} \\
& \Delta T_{i} \\
& C_{p} \\
& T_{0} \\
& \dot{m} \\
& \text { = Air pressures in collector, chimney }
\end{aligned}
$$

$P_{\text {el eff }}$

$\alpha_{i}$

$\rho_{o}(h), \rho_{i}(h)$

$g$

$R$

$T_{i}$

$q c, q r$

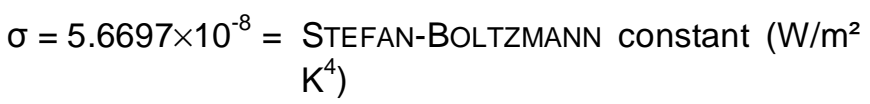
by the SUPP (MW)

= Efficiency parameter of collector ring-element $\Delta A_{\text {coll } i \text {. }}$

= Mass density of the air outside and inside $\mathrm{SC}\left(\mathrm{kg} / \mathrm{m}^{3}\right)$

$=$ Gravitational acceleration $\left(\mathrm{m} / \mathrm{s}^{2}\right)$

$=$ General gas constant for air $(\mathrm{J} / \mathrm{kg} \mathrm{K})$

$=$ Absolute temperature $(\mathrm{K})$

$=$ Heat transfers due to convection and radiation $\left(\mathrm{W} / \mathrm{m}^{2}\right)$

\section{REFERENCES}

[1] von Backström TW, Harte R, Höffer R, et al. State and recent advances of solar chimney power plant technology. Power Tech 2008; 88: 64-71.

[2] Schlaich J, Bergermann R, Schiel W, Weinrebe G. Design of commercial solar updraft tower systems. ASME J Sol Energy Eng 2005; 127: 117-24.

http://dx.doi.org/10.1115/1.1823493

[3] Schlaich J. The Solar Chimney, Electricity from the Sun. Stuttgart: Menges 1995.

[4] Krätzig WB. Physics, comp. simulation and optimization of thermo-fluidmechan. processes of solar updraft power plants. Solar Energy 2013; 98: 2-11.

http://dx.doi.org/10.1016/j.solener.2013.02.017

[5] Schindelin HW. Design of a $1500 \mathrm{~m}$ high tower of a SUPP. Diplom-Thesis, Univ. of Wuppertal 2002.

[6] Fluri TP. Turbine layout for and optimization of solar chimney power conversion units. Ph.D. Thesis, University of Stellenbosch 2008.

[7] Bernardes MA dos Santos. Technische, ökonomische und ökologische Analyse von Aufwindkraftwerken (Technical, economical, ecological analysis of SUPPs). Dr.-Ing.-Thesis, University of Stuttgart 2004.

[8] Gannon AJ, von Backström TW. Solar chimney turbine performance. ASME J Solar Energy Eng 2003; 125: 101-6. http://dx.doi.org/10.1115/1.1530195

[9] Kämmer K. Calculation of cross sections of flues In: CICIND Chimney Book, 57-77. CICIND; Zürich and Ratingen 2005.

[10] Duffie JA, Beckman WA. Solar Engineering of Thermal Processes, $3^{\text {rd }}$ ed. Hoboken New Jersey: Wiley \& Sons 2006.

[11] Pastohr H. Thermodynamische Modellierung eines Aufwindkraftwerks (Thermo-dynamic modeling of a SUPP. Dr.-Ing.-Thesis, Bauhaus Univ. Weimar 2004.

[12] Harte R, Höffer R, Krätzig WB, Mark P, Niemann H-J. Solar updraft power plants: Engineering structures for sustainable energy generation. Engineering Structures 2013; 56: 1698706.

http://dx.doi.org/10.1016/j.engstruct.2013.07.033

[13] Pretorius JP, Kröger DG. Solar chimney power plant performance. ASME J Solar Energy Eng 2006; 128: 302-11. http://dx.doi.org/10.1115/1.2210491 
[14] Pretorius JP. Optimization and Control of a Large-Scale Solar Chimney Power Plant. PhD-thesis, Univ. of Stellenbosch 2007.

[15] Haaf W, Friedrich K, Mayer G, Schlaich J. Solar chimneys. Int J Solar Energy 1983: 3-20; 1984: 141-161.

[16] Bergermann R, Weinrebe G. Realization and costs of solar updraft towers. In: Proceedings of the SCPT 2010 - Int. Conf. Solar Chimney Power Technology, 63-68. RuhrUniversity Bochum 2010.

[17] Lupi F, Borri C, Harte R, Krätzig WB, Niemann H-J. Facing technological challenges of Solar Updraft Power Plants. J Sound \& Vibration 2015; 334: 57-84. http://dx.doi.org/10.1016/j.jsv.2014.03.010
[18] Zhou XP, Yang JK, Xiao B, Shi XY. Special climate around a commercial solar chimney power plant. J Energy Engineering, ASCE 2008; 134: 6-14. http://dx.doi.org/10.1061/(ASCE)0733-9402(2008)134:1(6)

[19] Bottenbruch H, Harte R, Höffer R, Krätzig WB, Mark P, Niemann H-J, Eds. Proceedings SCPT 2010, $2^{\text {nd }}$ Int. Conf. Solar Chimney Power Technology, Ruhr-University Bochum and University Wuppertal, Germany 2010.

[20] Zhou XP, Ed. Proc. SUTPT 2012, $3^{\text {rd }}$ Int. Conf. on Solar Updraft Tower Power Technology. Huazhong Univ. of Science and Technology. Wuhan, China 2012.

Received on 12-02-2015

Accepted on 06-03-2015

Published on 15-06-2015

DOI: http://dx.doi.org/10.6000/1929-6002.2015.04.02.2

(C) 2015 Wilfried B. Krätzig; Licensee Lifescience Global.

This is an open access article licensed under the terms of the Creative Commons Attribution Non-Commercial License (http://creativecommons.org/licenses/by-nc/3.0/) which permits unrestricted, non-commercial use, distribution and reproduction in any medium, provided the work is properly cited. 